\title{
Prognostic Scale to Stratify Risk of Intrahospital Death in Patients with Acute Myocardial Infarction with ST-Segment Elevation
}

\author{
Ailed Elena Rodríguez-Jiménez MD MS, Tessa Negrín-Valdés MD, Hugo Cruz-Inerarity MD, Luis Alberto Castellano-Gallo MD, \\ Elibet Chávez-González MD PhD
}

\begin{abstract}
INTRODUCTION The scales available to predict death and complications after acute coronary syndrome include angiographic studies and serum biomarkers that are not within reach of services with limited resources. Such services need specific and sensitive instruments to evaluate risk using accessible resources and information.
\end{abstract}

OBJECTIVE Develop a scale to estimate and stratify the risk of intrahospital death in patients with acute ST-segment elevation myocardial infarction.

METHODS An analytical observational study was conducted in a universe of 769 patients with acute ST-segment elevation myocardial infarction who were admitted consecutively to the Camilo Cienfuegos Provincial Hospital in Sancti Spíritus Province, Cuba, from January 2013 to March 2018. The final study cohort included 667 patients, excluding 102 due to branch blocks, atrial fibrillation, drugs that prolong the QT interval, low life expectancy or history of myocardial infarction. The demographic variables of age, sex, skin color, classic cardiovascular risk factors, blood pressure, heart rate, blood glucose level, in addition to duration and dispersion of the QT interval with and without correction, left ventricular ejection fraction, and glomerular filtration rate were included in the analysis. Patients were categorized according to

\section{INTRODUCTION}

Cardiovascular disease is a global health problem. According to WHO, 17.8 million people worldwide died from cardiovascular disease in 2016 , with $52.8 \%$ of these deaths attributable to ischemic heart disease.[1] Ischemic cardiopathy is the cardiovascular disease with the highest morbidity and mortality, and acute myocardial infarction (AMI) is the most serious and causes the most deaths.[2,3] According to a report from the American Heart Association, every 40 seconds, a US person suffers an AMI, although mortality from this cause decreased by $14.6 \%$ between 2006 and 2016 in the United States; however, approximately 550,000 first episodes and 200,000 recurrent episodes of acute myocardial infarction occur annually.[4]

In Europe, national records of countries in the European Society of Cardiology reveal intrahospital mortality at $4 \%-12 \%$, while annual AMI mortality is approximately $10 \%$.[2]

Eighty percent of deaths from AMI occur in low- and middle-income countries, where there is scarcity of therapeutic resources that

\section{IMPORTANCE}

The scale designed permits estimation and stratification of intrahospital death risk for patients with ST-segment elevation myocardial infarction, using conventional clinical tools without the need to obtain angiographic studies or serum biomarkers in cardiac care units with limited resources. the Killip-Kimball Classification for degree of heart failure. A risk scale was constructed, the predictive ability of which was evaluated using the detectability index associated with an receiver-operator curve.

RESULTS Seventy-seven patients died (11.5\%). Mean blood glucose levels were higher among the deceased, while their systolic and diastolic blood pressure, left ventricular ejection fraction, and glomerular filtration rate were lower than those participants discharged alive. Relevant variables included in the scale were systolic blood pressure, Killip-Kimball class, cardiorespiratory arrest, glomerular filtration rate, corrected QT interval dispersion, left ventricular ejection fraction, and blood glucose levels. The variable with the best predictive ability was cardiorespiratory arrest, followed by a blood glucose level higher than $11.1 \mathrm{mmol} / \mathrm{L}$. The scale demonstrated a great predictive ability with a detectability index of 0.92 .

CONCLUSIONS The numeric scale we designed estimates and stratifies risk of death during hospitalization for patients with ST-segment elevation myocardial infarction and has good metric properties for predictive ability and calibration.

KEYWORDS ST-segment elevation myocardial infarction, mortality, risk assessment, Cuba

meet international treatment guidelines.[5] The ability to predict the risks of complications and death with a scale that does not require angiography or serum biomarkers is an attractive prospect for these countries.

In Cuba, the mortality rate from heart disease in 2018 was 228.6 deaths per 100,000 population, with $63.3 \%$ of these deaths due to ischemic heart disease. For AMI, the mortality rate was 65.3 deaths per 100,000 population, of which $45.2 \%$ of deaths were due to ischemic heart disease. In Sancti Spíritus Province, in the center of the country, heart disease is also a health issue with a crude death rate of 237.9 deaths per 100,000 population and an age-adjusted death rate of 109.7 deaths per 100,000 population.[6]

Ischemicheartdiseasecan beclassifiedasanacutecoronarysyndrome, with or without ST-segment elevation, depending on the recording of at least two contiguous leads of the surface electrocardiogram (ECG). [5] In acute ST-segment elevation myocardial infarction (STEMI), risk of complications and death is high despite advances in diagnosis and treatment of the condition. Prognosis for STEMI patients is related to the probability of developing short- or long-term complications and depends more on the state of the patient at the time of admission than on prior coronary risk factors.[2,5]

Efforts to develop models to quantify risk of complications or death for a patient with AMI using a scoring system started in the early 1950s,[7] and expanded as specialized coronary care units began to appear. In recent years, prediction models or algorithms have been developed that use serum biomarkers and clinical, electrocardiographic and angiographic variables to evaluate risk 
with greater precision and accuracy.[8] Despite the wide variety of proposed models $[9,10]$ and the simplicity of some of them, $[11,12]$ their use in clinical practice is limited, as they are highly dependent on availability of resources, primarily those relying on serum biomarkers.

High-income countries implement international treatment guidelines for AMI treatment[2,3] but these guidelines have limited applicability in low- and middle-income countries due to difficulty accessing more modern therapeutic resources. A 2014 study by Shimony[13] revealed that patients in low- and middle-income countries are less likely to receive treatment with percutaneous transluminal coronary angioplasty (PTCA) than those in high-income countries (4.9\% compared to $45.6 \%)$, and that thrombolytic therapy was more common in low- and middleincome countries (72.5\% compared to $38.9 \%)$. These disparities in AMI treatment are reflected in mortality rates that are higher in low- and middle-income countries.[5] A study evaluating regional differences in AMI mortality at two years showed that the highest rates were reported in Latin America (7.4\%) and the lowest in northern Europe (2.5\%).[14] The differences in therapeutic options for these patients force low- and middle-income countries to look for risk stratification alternatives that allow them to decrease mortality while optimizing resources.

Risk estimation and stratification usually rely on analytical resources that combine the effects of different variables.[15] All risk scores designed thus far have their strengths and weaknesses, and their application is limited to the populations that served as the basis for their construction. The Global Registry of Acute Coronary Events (GRACE)[16] is the best-studied and validated instrument in the world,[17] but it contains elements that are not accessible for many low- and middle-income countries, such as measuring serum troponins.[7] The Thrombolysis in Myocardial Infarction (TIMI) Risk Score is an easy model to apply, but it was designed in the course of clinical trials, which has led its usefulness in daily practice to be called into question.[7,12] A meta-analysis that included 42 validated studies on 31,625 patients recognized TIMI and GRACE as the only duly validated scores. The TIMI score has lower predictive ability $(C=0.77)$ than the GRACE $(\mathrm{C}=0.82)$.[17]

Advances in AMI treatment allow providers to offer patients multiple therapeutic options depending on the severity of the disease and its prognosis. For this reason, there is still interest in determining the risks of complications and mortality with precision and accuracy. Considering the limitations of current algorithms and their application in coronary care units with limited resources, sensitive prognostic models must be developed to concentrate efforts and expenses on higher-risk patients, thereby improving risk-benefit and cost-effectiveness indicators.

The hospital where this research was conducted does not have the resources needed to perform modern reperfusion techniques, such as PTCA and use of fibrin-specific thrombolytic agents. [2] This further supports the need to more accurately estimate and stratify the initial risk of complications and death in STEMI patients in the days following AMI.

The objective of this study was to create a scale to estimate and stratify risk of intrahospital mortality for STEMI patients.

\section{METHODS}

Design and population An observational analytical study was conducted on STEMI patients admitted consecutively to the coronary care unit at the Camilo Cienfuegos Provincial Hospital (HPCC) in Sancti Spíritus Province, Cuba, between January 1, 2013 and March 31, 2018. A total of 769 patients were registered, with 667 included and 102 excluded for the following reasons: 31 due to left bundle branch block of His, 19 due to prior atrial fibrillation, and 14 with medications that prolong the QT interval. These are all conditions that may make it difficult to take electrocardiographic measurements. Patients with conditions unrelated to the current ischemic event that considerably worsen prognosis were excluded from the study, including 23 patients with a history of myocardial infarction. Another 15 patients who were excluded due to a life expectancy of less than one year from non-cardiac conditions. Average age was 67.4 years (SD = 12.8). Of all participating patients, $441(66.1 \%)$ were men and 226 $(33.9 \%)$ were women.

In the absence of left ventricular hypertrophy and left bundle branch block, STEMI requires $\geq 2 \mathrm{~mm}$ of ST elevation (measured at $\mathrm{J}$ point) in two contiguous ECG leads in men $\geq 40$ years old according to the ACC/AHA definition. A total of $\geq 2.5 \mathrm{~mm}$ is required in men $<40$ years old, and only $1.5 \mathrm{~mm}$ required in women of any age in the $\mathrm{V}_{2}-\mathrm{V}_{3}$ leads, or $\geq 1.0 \mathrm{~mm}$ in other leads.[2]

Study variables Age, sex, and skin color (white, brown, or black), were recorded, the latter variable determined by observers trained in this type of study. The following were considered cardiovascular risk factors: arterial hypertension (>140/90 $\mathrm{mmHg}$ ), prior ischemic heart disease, hypercholesterolemia (cholesterol $>6.71 \mathrm{mmol} / \mathrm{L}$, according to established reference values), tobacco use, obesity (body mass index $>30 \mathrm{~kg} / \mathrm{m}^{2}$ ), history of diabetes mellitus and history of chronic obstructive pulmonary disease (COPD).[18] Systolic blood pressure (SBP), diastolic blood pressure (DBP) and heart rate $(\mathrm{HR})$ upon admission were considered clinical variables.

The degree of acute heart failure was evaluated using the KillipKimball classification[19] based on the following criteria:

Class I: No heart failure (no clinical signs of cardiac decompensation)

Class II: Heart failure: (rales in the lower half of lung fields, S3

gallop, and pulmonary venous hypertension)

Class III: Severe heart failure (frank pulmonary edema with crackling rales in all lung fields)

Class IV: Cardiogenic shock: (hypotension defined as systolic blood pressure $<90 \mathrm{mmHg}$ and evidence of peripheral vasoconstriction, such as oliguria, cyanosis and diaphoresis)

- Killip I: no clinical signs of heart failure,

- Killip II: rales in the lungs, third heart sound (S3), and elevated jugular venous pressure,

- Killip III: acute pulmonary edema (APE), and

- Killip IV: cardiogenic shock or arterial hypotension (measured as systolic blood pressure $<90 \mathrm{mmHg}$ ), and evidence of peripheral vasoconstriction (oliguria, cyanosis, and diaphoresis)

Values for blood glucose, leukocytes, creatinine, uric acid and total cholesterol were determined. Blood was drawn from the antecubital vein within 24 hours of the patient's admission and 
was processed using a Hitachi High-Technologies Corporation Cobas C311 Analyzer (Tokyo, Japan).

When possible, pharmacological thrombolysis was performed as a reperfusion procedure with 1,500,000 IU of Heberkinasa (recombinant streptokinase, Centro de Ingeniería Genética y Biotecnología, Cuba) administered intravenously.[20] This procedure was not performed on 307 patients for the following reasons: 127 (41.4\%) due to long ischemic time (lapse from symptom onset to hospital arrival) $>12$ hours; 82 (26.7\%) without precise initial diagnosis of AMI; 37 (12.1\%) in cardiogenic shock; 21 (6.8\%) with hemorrhagic stroke; 14 (4.6\%) in prolonged cardiac arrest; 11 (3.6\%) with known hemorrhagic disorders; 9 (2.9\%) reporting a transient ischemic attack in the previous 6 months; and $6(2.0 \%)$ with a history of gastrointestinal hemorrhaging in the last month.

The infarction was localized via ECG performed on admission and classified according to the Bayés de Luna criteria (extensive anterior, mid-anterior, apical-anterior, septal, inferior, inferolateral, and lateral).[21] Among the complications studied were newly detected atrial fibrillation confirmed via surface ECG upon admission, high-grade and grade III atrioventricular blockage, recurring infarction (when signs and symptoms of acute coronary failure were repeated during admission after the first infarction) [22] and death.

The left ventricular ejection fraction (LVEF) was estimated using the Simpson biplane method[23] using a transthoracic echocardiogram with Aloka Alpha 5 equipment (Tokyo, Japan). The echocardiogram was performed when patients were hemodynamically stable with no signs of arterial hypotension, extreme bradycardia or arrhythmias.

Renal glomerular filtration rate (GFR) was calculated with the Cockcroft-Gault formula[24] using the obtained creatinine values.

GFR $[\mathrm{mL} / \mathrm{min}]=(140$ - age [years] $) \times$ weight $[\mathrm{kg}] /$ Serum creatinine $[\mathrm{mmol} / \mathrm{L}] \times 0.81$

For women, the expression above is multiplied by 0.85 .

Electrocardiogram variables A 12-lead ECG was performed upon admission, before thrombolysis, and was repeated at 90 minutes. Electrocardiographic variables were taken from the first ECG and with patients who underwent thrombolysis, reperfusion signs were analyzed from the 90-minute ECG. ECGs were performed at a sweep speed of $25 \mathrm{~mm} / \mathrm{s}$ with standardization set at $10 \mathrm{~mm} / \mathrm{mV}$, using a Cardiocid BB electrocardiograghy (Central Institute for Digital Research, Cuba)[25] with a bandpass filter restricting spectrum frequencies to $0.05-150 \mathrm{~Hz}$ and a comb filter for electrical hum at $60 \mathrm{~Hz}$. Two observers used a magnifying glass to manually and independently measure the following parameters in all ECG leads:

QT interval (QTi): time in milliseconds from the start of QRS complex to the end of the $T$ wave, defined as the point of ventricular repolarization of the $\mathrm{T}$ wave to the isoelectric line or the nadir between the $T$ wave and the $U$ wave if present.[26] This was measured in all the leads and the average calculated. Corrected QTi (QTc), estimated using the Bazett's formula.[27] QT dispersion (QTd): QTi measured in the 12 ECG leads, calculating difference between maximum and minimum values.
Rate-corrected QTd (QTcd): QTi measured in the 12 ECG leads corrected with Bazett's formula,[27] the difference calculated between maximum and minimum values.

ST elevation $>1 \mathrm{mV}$ : Measured in all ECG leads in which ST elevation is observed from the baseline to the $\mathrm{J}$ point, and the TP segment is considered more isoelectric.

ST depression $>1 \mathrm{mV}$ : Measured in all ECG leads in which the ST depression is observed from the baseline to the point of greatest ST-segment depression and the TP segment is considered more isodiphasic.

ST elevation in the aVR lead: ST-segment elevation is recorded at $\geq 1 \mathrm{~mm}$ in this lead.

Data collection, processing and management Cardiologists performed initial patient evaluations and clinical followup. The hospital stay lasted five to seven days. Data was collected via hospital registration forms for the variables being studied.

A database was created using the SPSS statistical package version 21.0 for Windows (IBM). Continuous data were summarized with mean $(\mathrm{m})$ and standard deviations (SD). For categorical data, absolute numbers and percentages were used. These descriptive statistics were calculated for both the living and deceased patients.

The heuristic for the creation of the scale is based on application of a classification model (classification tree) and a prediction model (binary logistic regression), the results of which were used to select the set of variables for later use in creating the scale, along with a criterion of parsimony to avoid information redundancy. The tree would provide evidence for choosing the optimal intercepts for each variable, and the regression model would be used to provide quantitative approximations the appropriate weights.

The number of categories ( 2 for cardiac arrest and 4 for the other variables) and the values on the scale were determined and assigned considering the criteria from the literature.[2,3,5,28,29] Categories were assigned between 0 and 3 , except for cardiac arrest, which, due to its severity, was categorized as 0 (no) or 3 (yes). These categories and their significance are summarized below:

Cardiac arrest: 0, no; 3 , yes

Blood glucose level: 0, $\leq 6.1 \mathrm{mmol} / \mathrm{L} ; 1,6.2-7.7 \mathrm{mmol} / \mathrm{L} ; 2,7.8-$ $11.1 \mathrm{mmol} / \mathrm{L} ; 3,>11.1 \mathrm{mmol} / \mathrm{L}$

SBP: 0, >100 mmHg; 1, 90-100 mmHg; 2, 60-89 mmHg; 3, <60 $\mathrm{mmHg}$

GFR: 0, $\geq 90 \mathrm{~mL} / \mathrm{min} ; 1,60-89 \mathrm{~mL} / \mathrm{min} ; 2,30-59 \mathrm{~mL} / \mathrm{min} ; 3,<30$ $\mathrm{mL} / \mathrm{min}$

QTcd: 0, <40 ms; 1, 40-59 ms; 2, 60-79 ms; 3, $\geq 80 \mathrm{~ms}$

Killip-Kimball class: 0, Class I; 3, Class IV

LVEF: $0, \geq 55 \%$; 1, 45-54\%; 2, 30-44\%; 3, <30\%

The adjusted odds ratios (OR) were chosen as weights for the scale categories, rounding the results of the binary logistic regression model to the nearest whole number (except for the Killip-Kimball class which is rounded to the next highest whole number). Thus, the ORs are as follows: of QTcd $=2.18 \approx 2$; of GFR $=1.87 \approx 2$; of cardiac arrest $=3.17 \approx 3$; of SBP $=1.65 \approx$ 2 ; of blood glucose level $=2.62 \approx 3$; of LVEF $=1.92 \approx 2$ and of Killip-Kimball class $=1.27 \approx 2$. The total score was obtained as a scalar product of the values of the variables, organized by their 
weights. The result is a scale we named EERIAM-HCC (in Spanish 'Escala de Estratificación de Riesgo para el Infarto Agudo del Miocardio del Hospital Camilo Cienfuegos'), the Camilo Cienfuegos Hospital's risk stratification scale for the AMI. It uses values between 0 (for a patient in the most favorable condition for all variables) and 48 (for a patient in the most unfavorable condition). After calculating their 10th, 25th, 50th, 75th, and 90th percentiles, this scale was then transformed into an ordinal scale with four levels:

Low risk: <25th percentile

Moderate risk: 25th-74th percentiles

High risk: 75th-89th percentiles

Extreme risk: $\geq 90$ th percentile

The discriminatory power of the EERIAM-HCC scale for intrahospital mortality is estimated using the receiveroperator curve (ROC) using estimates and the 95\% confidence interval $(\mathrm{Cl})$ area under the curve. Calibration (the relationship between the observed and expected risk) was evaluated using the Hosmer-Lemeshow chisquare goodness-of-fit test. Traditionally, a value of $p$ $>0.05$ associated with this test suggests an acceptable calibration of the model.

Ethics The study was approved by the hospital's Research Ethics Committee. The design respected the principles of the Declaration of Helsinki,[30] the Norms of the Council of International Organizations of Medical Sciences (WHOCIOMS),[31] and the principles of good clinical practices. Each patient received a description of the research, including its risks and benefits. Written informed consent was obtained from patients, or from an immediate family member when patients were in extremely critical condition or had lost consciousness. The study design did not include manipulation of variables and followed the protocol established at the hospital for AMI treatment. The tests and interventions were conducted by qualified personnel, with the necessary care taken to minimize risks in accordance with good clinical practice guidelines. Selection of laboratory methods followed the principles of maximum beneficence and non-maleficence in accordance with good laboratory practice guidelines.

Data were encrypted and names were not included in the databases, nor was any other information that could be used to identify participating patients, in order to respect their privacy and confidentiality.

\section{RESULTS}

Case fatality was $11.5 \%$ with 77 deceased patients, of which $49(63.6 \%)$ were men. The average age was similar in both groups, as was distribution by sex (Table 1).

Results (Table 1) that distinguish the deceased patients from those who survived were notably higher values for the duration and dispersion of measured and corrected QTi, of the QRS complex and of blood glucose levels, as well as notably lower values of GFR and LVEF (Table 1).

Also notable are the differences between the two groups in frequency of cardiac arrest, atrial fibrillation, infarction
Table 1: Baseline characteristics of patients included in the study \begin{tabular}{|l|l|l|}
\hline Variables & Deaths $77(11.5 \%)$ & Alive $590(88.5 \%)$
\end{tabular} Demographic variables

\begin{tabular}{lrr} 
Age & $68.9(\mathrm{SD}=11.9)$ & $67.2(\mathrm{SD}=12.9)$ \\
\hline Female & $28(36.4 \%)$ & $198(33.6 \%)$ \\
\hline Male & $49(63.6 \%)$ & $392(66.4 \%)$ \\
White skin color & $55(71.4 \%)$ & $437(74.1 \%)$ \\
Brown skin color & $14(18.2 \%)$ & $102(17.3 \%)$ \\
\hline Black skin color & $8(10.4 \%)$ & $51(8.6 \%)$ \\
\hline Risk factors & & \\
\hline Arterial hypertension & $60(77.9 \%)$ & $469(79.5 \%)$ \\
\hline Diabetes mellitus & $35(45.5 \%)$ & $165(28.5 \%)$ \\
Hypercholesterolemia & $13(16.9 \%)$ & $83(14.1 \%)$ \\
\hline Tobacco use & $36(46.8 \%)$ & $344(58.3 \%)$ \\
\hline Prior ischemic cardiomyopathy & $39(50.6 \%)$ & $258(43.7 \%)$ \\
Obesity & $18(23.4 \%)$ & $165(28.0 \%)$ \\
COPD & $16(20.8 \%)$ & $138(23.4 \%)$ \\
\hline Clinical vara & &
\end{tabular}

Clinical variables on admission

Heart rate (beats/min)

$86.8(\mathrm{SD}=24.5) \quad 80.8(\mathrm{SD}=24.3)$

Systolic blood pressure $(\mathrm{mmHg})$

Diastolic blood pressure $(\mathrm{mmHg})$

$88.5(\mathrm{SD}=33.1) \quad 116.2(\mathrm{SD}=38.7)$

Topography of infarction

$\begin{array}{lll}\text { Apical-anterior } & 15(19.5 \%) & 61(10.3 \%)\end{array}$

Extensive anterior $\quad 26(33.8 \%) \quad 76(12.9 \%)$

$\begin{array}{lll}\text { Mid-anterior } & 14(18.2 \%) & 119(20.2 \%)\end{array}$

Inferior

Inferior plus right ventricle

Infero-lateral

Lateral

Septal

$265(44.9 \%)$

$2(2.6 \%) \quad 11(1.9 \%)$

$3(3.9 \%) \quad 38(6.4 \%)$

$5(6.5 \%) \quad 16(2.7 \%)$

Electrocardiogram variables

Duration of measured QTi (ms)

Duration of corrected QTi (ms)

$0(0.0 \%)$

$4(0.7 \%)$

Dispersion of measured QTi (ms)

$434.7(\mathrm{SD}=51.0) \quad 397.4(\mathrm{SD}=50.6)$

$510.1(\mathrm{SD}=90.1) \quad 450.8(\mathrm{SD}=85.5)$

$77.8(\mathrm{SD}=19.9) \quad 56.2(\mathrm{SD}=25.5)$

Dispersion of corrected QTi (ms)

Duration of QRS (ms)

Dispersion of QRS (ms)

ST elevation of $>1 \mathrm{mV}$

$91.4(\mathrm{SD}=27.3) \quad 63.9(\mathrm{SD}=30.9)$

$103.0(\mathrm{SD}=8.7) \quad 97.1(\mathrm{SD}=8.2)$

$41.6(\mathrm{SD}=13.0) \quad 35.7(\mathrm{SD}=12.2)$

$167(28.3 \%)$

ST depression of $>1 \mathrm{mV}$

$20(26.0 \%)$

$155(26.3 \%)$

ST elevation in the aVR lead

$8(10.4 \%)$

$12(2.0 \%)$

Reperfusion therapy

Thrombolysis

Reperfusion*

$45(58.4 \%)$

$8(17.8 \%)$

$315(53.4 \%)$

Ischemic time (minutes) $248.0(S D=184.9) 235.6(S D=149.1)$

Blood chemistry

Blood glucose levels $\mathrm{mmol} / \mathrm{L}$

$8.6(\mathrm{SD}=2.8) \quad 7.0(\mathrm{SD}=1.7)$

Creatinine $\mu \mathrm{mol} / \mathrm{L}$

Uric acid $\mathrm{mmol} / \mathrm{L}$

$112.2(S D=34.8) \quad 88.5(S D=20.8)$

Cholesterol $\mathrm{mmol} / \mathrm{L}$

$367.4(S D=105.6) \quad 370.1(S D=100.3)$

$4.8(\mathrm{SD}=1.6) \quad 4.8(\mathrm{SD}=1.5)$

Ciometrics

Absolute leukocyte values (x 10\%/L)

Complications

Newly detected atrial fibrillation

Recurring AMI

ECG upon admission

Atrioventricular block

MACE

Killip-Kimball Case

Class I

Class II

Class III

Class IV

Other variables

FGR $\mathrm{mL} / \mathrm{min}$

LVEF

$22(28.6 \%)$

$20(26.0 \%)$

$59(10.0 \%)$

$48(62.3 \%)$

$46(7.8 \%)$

$4(5.2 \%)$

$44(7.5 \%)$

$77(100 \%)$

$44(7.5 \%)$

$85(14.4 \%)$

*Percentage in relation to total thrombolyzed patients.

COPD: chronic obstructive pulmonary disease

QTi: QT interval

AMI: acute myocardial infarction

MACE: major adverse cardiovascular events 
Table 2: Intrahospital deaths per ordinal categories of the EERIAMHCC Scale (predictive ability and calibration)

\begin{tabular}{l|r|r|r|}
\hline Risk level & N & Deaths & $\%$ \\
\hline Low (0-9 points) & 146 & 0 & 0.0 \\
\hline Moderate (10-19 points) & 347 & 11 & 3.2 \\
\hline High (20-25 points) & 101 & 19 & 18.8 \\
\hline Extreme ( $\geq 26$ points) & 73 & 47 & 64.4 \\
\hline
\end{tabular}

Predictive ability $\mathrm{C}=0.93$ Calibration (Hosmer-Lemeshow) $\mathrm{p}=0.85$

EERIAM-HCC: Escala de Estratificacion de Riesgo en el Infarto Agudo del

Miocardio Hospital Camilo Cienfuegos

recurrence, atrioventricular block, and diabetes, with this last factor being particularly high among the deceased.

Previous extensive apical myocardial infarction was much more frequent in the deceased patients, as was the number of cases in Killip-Kimball class IV (Table 1).

Proceeding through the nodes and branches of the regression tree (Figure 1), we see the following notable results:

Cardiac arrest is the event with the worst prognosis and the one that most distinguishes the response variable (alive or deceased). The risk ratio of death associated with cardiac arrest is $>10$ (52.2\% for those with cardiac arrest and only $5 \%$ for those without cardiac arrest). In patients who did not suffer cardiac arrest (node 1) the risk increased $5 \%$ to $45.8 \%$ if initial blood glucose level was $>11.1 \mathrm{mmol} / \mathrm{L}$.
Figure 2: Logistic regression with the main mortality predictors obtained from the classification tree

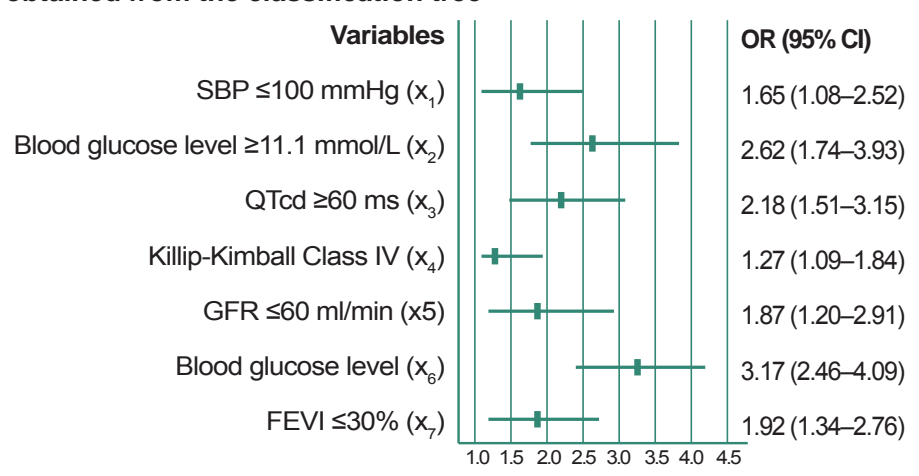

SPB: systolic blood pressure QTc: corrected QTi

Qtd: difference between maximum and minimum values

GFR: renal glomerular filtration rate FEVI: forced expiratory volume

Only $3.3 \%$ of patients who did not suffer from cardiac arrest and whose blood glucose levels were $<11.1 \mathrm{mmol} / \mathrm{L}$ died, but that risk quintupled if the patient was in Killip-Kimball class IV. If the patient was not in the Killip-Kimball class IV and their LVEF was $>30 \%$, risk of death was reduced to $<1 \%$.

On the right branch of the tree, which corresponds to the patients who suffered cardiac arrest, the risk is always higher than $50 \%$

Figure 1: Classification tree with predictors of death

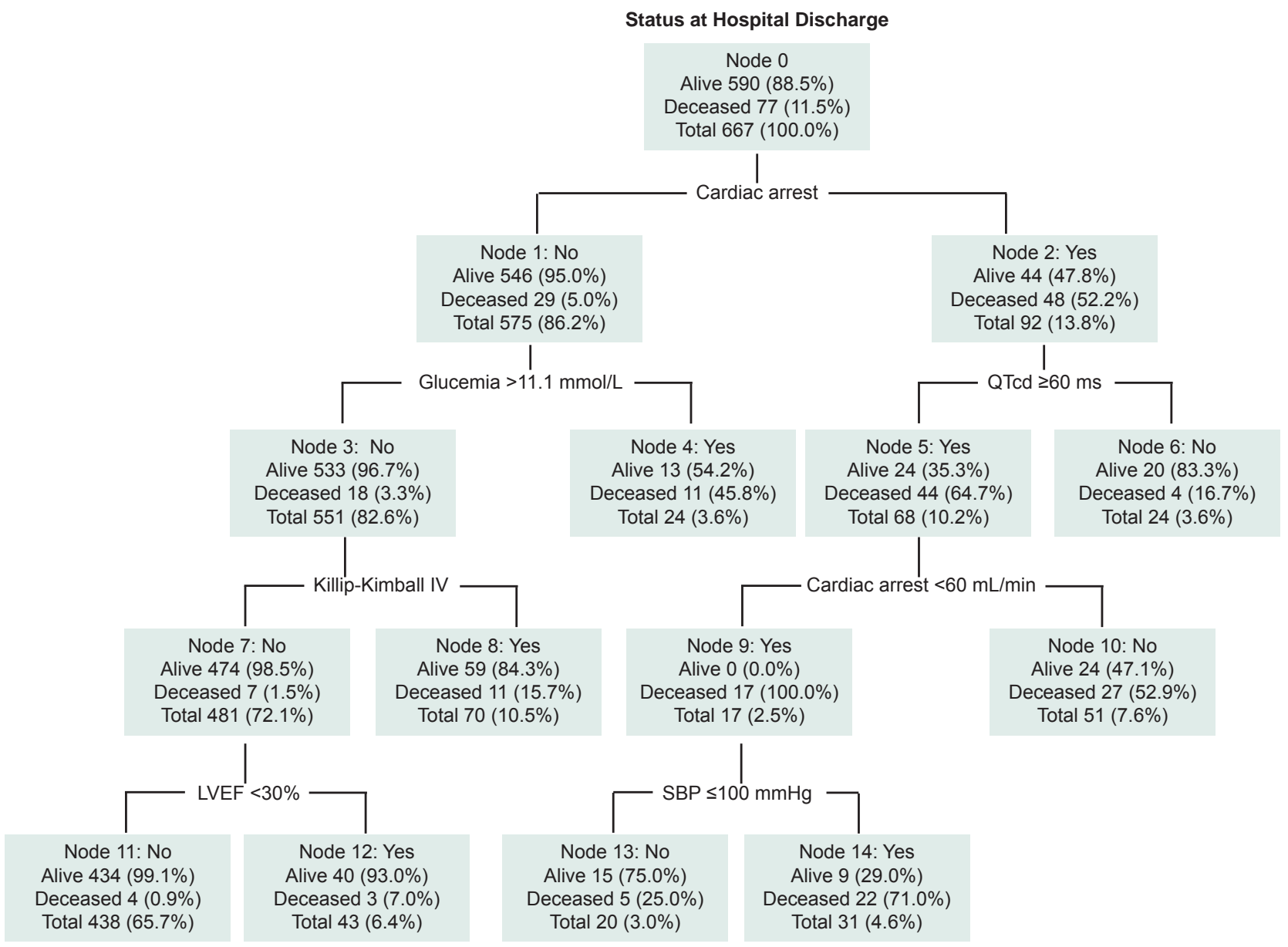


except for those with QTcd $<60 \mathrm{~ms}$, for whom the risk is reduced. The adjusted ORs for covariates provided by the binary logistic regression model (Figure 2) provide an approximate measure of the relative importance of each variable as a predictor of intrahospital death, and are the basis for the creation of the scale established below.

New risk stratification scale for patients with STEMI is a quantitative scale that converts values between 0 and 48 points into an ordinal scale with four categories based on percentile distribution. Factors included in the scale were SBP, Killip-Kimball class, cardiac arrest, GFR, QTcd, LVEF and blood glucose level.

Most patients had between 10 and 19 points, which corresponds to moderate risk. None of the patients had the maximum number of points and only one deceased patient was close, with 44 points. A clear positive association is observed between the points on the scale and case fatality (Table 2 ).

\section{DISCUSSION}

The patients involved in the design of the EERIAM-HCC scale did not undergo PTCA, as established in the international treatment guides for myocardial infarction, as there is no hemodynamic service in the hospital's coronary care unit.[2,3]

The new risk stratification scale for patients with STEMI combines variables that are easily acquired at a patient's bedside, including QTi dispersion, which has been associated with greater severity of coronary artery disease,[32] higher incidence of ventricular arrhythmias,[33,34] and greater recurrence of infarction.[35] No other scale was found in the reviewed literature that included the QTi dispersion; however, QTi prolongation after STEMI was included in the scale designed by Rivera[36] in 2016.

Bordejevic[37] found that SBP $<105 \mathrm{mmHg}$ was associated with greater intrahospital mortality, even after PTCA had been performed. [37] SBP $<100 \mathrm{mmHg}$ is included as a predictor in both the TIMI[12] and GRACE[16] scales.

The importance of including GFR as a variable is based on indications that patients with chronic kidney disease and diminished kidney function have a greater risk of death and complications in the course of an AMI. Vavalle[38] studied 5244 STEMI patients and found a relationship between worsening renal function after PTCA and renal dysfunction in patients before their AMI. Gutiérrez and Martos Benítez [39] found that Cuban patients who were admitted with AMI and died had worse renal function based on their creatinine and GFR values. Granger[16] found that for every $88 \mu \mathrm{mol} / \mathrm{L}$ increase in creatinine, risk of death increased $19 \%-29 \%(95 \% \mathrm{Cl} 1.19-1.29)$ and risk of AMI increased $8 \%-16 \%(95 \% \mathrm{Cl} 1.08-1.16)$. Renal function is one of the variables included in the GRACE prognostic score.[16]

High blood glucose levels implies worse prognosis for those with acute coronary syndrome, in both diabetic and non-diabetic patients, and is included in the EPICOR scale.[40] Ding[41] found greater mortality in non-diabetic AMI patients when their blood glucose was $>10.0 \mathrm{mmol} / \mathrm{L}$. Stress hyperglycemia is common in AMl patients even without a prior diagnosis of diabetes mellitus.[2,3]

The five-year follow-up for a cohort of STEMI patients who were not diagnosed with diabetes mellitus showed that stress hyperglycemia implied a greater risk of death (relative risk, $\mathrm{RR}=1.45 ; 95 \% \mathrm{Cl}$ 1.06-1.98; $p=0.021$ ) and of readmission for heart failure (RR $=1.48 ; \mathrm{Cl}$ al $95 \%=1.04-2.10 ; p=0,031)$; however, in diabetic patients it did not imply a worse prognosis (mortality $\mathrm{RR}=1.0$; $95 \% \mathrm{Cl} 0.68-1.48 ; p=0.996$ or readmissions due to heart failure $\mathrm{RR}=1.31 ; 95 \% \mathrm{Cl} 0.90-1.89 ; \mathrm{p}=0.154)$. [42] These findings may suggest a greater tolerance to hyperglycemia in diabetic patients. There are debates regarding what constitutes optimum control of blood sugar levels in AMI patients with acute myocardial ischemia. [43] Lacking sufficient evidence on the matter, the current guidelines recommend starting hypoglycemic treatment with insulin when blood glucose levels reach $\geq 10 \mathrm{mmol} / \mathrm{L}$ and avoiding hypoglycemia at levels $<3.9 \mathrm{mmol} / \mathrm{L}$.[2]

Mortality was much higher in patients with cardiac arrest, consistent with studies using the GRACE score[16] and ACTION-GWTG.[10] Cardiac arrest caused by ventricular arrhythmias occurs with greater frequency in patients with an ischemic time $>12$ hours before receiving medical care, incomplete revascularization, cardiogenic shock, infarctions that affect a large portion of the myocardial tissue, and preexisting arrhythmogenic substrate.[44]

In this study, Killip-Kimball Class I was most common in patients who were discharged alive and Class IV most common in deceased patients. A recent multicenter registry showed an association between heart failure and mortality at 30 days postAMI in STEMI patients.[45] Cardiogenic shock (Killip-Kimball Class IV) is the main cause of death in myocardial infarction and presents as a complication in $6 \%-10 \%$ of all cases. Early death from cardiogenic shock is higher than 50\%.[46] In a cohort of 112,668 survivors of myocardial infarction, $4.9 \%$ presented with cardiogenic shock, and a year later, readmissions and deaths from all causes among these patients increased (adjusted OR = $1.1 ; 95 \%$ Cl 1.02-1.18).[47]

LVEF is a recognized predictor of long- and short-term complications after myocardial infarction.[29] In a multivariate prediction model for risk based on echocardiographic variables, LVEF was an independent predictor (hazard ratio $=1.45,95 \% \mathrm{Cl} 1.02-2.08 ; p=$ 0.040 ) and the risk prognosis was inversely proportional to LVEF when it was $<40 \%$.[48] Schwaiger[49] demonstrated a greater incidence of complications in patients with LVEF $<52 \%$ (hazard ratio $=2.57 ; 95 \% \mathrm{Cl} 1.1-6.2 ; \mathrm{p}=0.036$ ) in STEMI patients with topographies that did not involve the anterior face.

The EERIAM-HCC scale developed in our study demonstrated a good discriminative ability $(C=0.92)$, higher than the $C=0.88$ of the ACTION-GWTG score[10], which is consistent with results of this study in the predictive variables of cardiac arrest and the degree of heart failure, GFR and SBP_although this is based on a contemporary record of patients in the United States and includes troponins for estimating prognosis. TIMI,[12] which was used to predict death at 30 days post-AMI, has a $\mathrm{C}=0.77$ and is consistent with our EERIAM-HCC scale in the SBP and Killip-Kimball class variables. For predicting death at 6 months, GRACE[16] has $\mathrm{C}=$ 0.82 and includes among its variables renal function, as does our scale. Conventionally, if the area under the curve has a $C$ value greater than 0.9 , the test is considered to have very good predictive power; $\mathrm{C}$ values between $0.7-0.9$ are considered to have moderate predictive power; and values between 0.5-0.7, are considered to have poor predictive power.[50] 
No significant differences were found between the frequency of cases observed and expected according to the HosmerLemeshow goodness-of-fit test, indicating the scale is well calibrated.

One study limitation is that PTCA was never performed on patients in the cohort due to material limitations, and that the percentage of patients who undergo thrombolysis is low, which would explain the high mortality rate of the cohort. However, these results are useful for low- and middle-income countries requiring methods to provide quality medical care with limited resources. Another limitation in this first approximation is that the study did not analyze the outcomes or usefulness of the proposed scale in relation to additional variables such as age, sex and skin color, which should be considered in depth.

\section{CONCLUSIONS}

The relevant variables for the EERIAM-HCC scale to predict mortality and complications are cardiac arrest, blood glucose level, LVEF, QTcd, Killip-Kimball class, SBP and GFR.

The scale's predictive ability and good calibration demonstrate its usefulness in stratifying risk of death for AMI patients with STsegment myocardial infarction during the first seven days of hospitalization in coronary care units in Cuba and other settings where angiography and serum biomarkers are not readily available. $-1 /$ -

\section{REFERENCES}

1. World Health Statistics 2019: monitoring health for the SDGs, sustainable development goals. Geneva: World Health Organization; 2019 [cited 2019 Oct 2]. Available at: https://www.who.int/gho/ publications/world_health_statistics/2019/en/

2. Ibanez B, James S, Agewall S, Antunes MJ, Bucciarelli-Ducci C, Bueno H, et al. 2017 ESC Guidelines for the management of acute myocardial infarction in patients presenting with ST-segment elevation: The Task Force for the management of acute myocardial infarction in patients presenting with ST-segment elevation of the European Society of Cardiology (ESC). Eur Heart J [Internet]. 2018 Jan 7 [cited 2019 Oct 2];39(2):119-77. Available at: https://doi .org/10.1093/eurheartj/ehx393

3. O'Gara PT, Kushner FG, Ascheim DD, Casey DE Jr, Chung MK, De Lemos JA, et al. 2013 ACCF/AHA guideline for the management of ST-elevation myocardial infarction: a report of the American College of Cardiology Foundation/ American Heart Association Task Force on Practice Guidelines. J Am Coll Cardiol [Internet]. 2013 [cited 2019 Oct 2];61(4):e78-e140. Available at: https://doi.org/10.1016/j.jacc.2012.11.019

4. Benjamin EJ, Muntner P, Alonso A, Bittencourt MS, Callaway CW, Carson AP, et al. Heart Disease and Stroke Statistics-2019 Update: A Report from the American Heart Association. Circulation [Internet]. 2019 Mar 5 [cited 2019 Oct 2];139(10):e56-e528. Available at: https://doi .org/10.1161/CIR.0000000000000659

5. Anderson JL, Morrow DA. Acute myocardial infarction. N Engl J Med [Internet]. 2017 May 25 [cited 2019 Oct 2];376(21):2053-64. Available at: https://doi.org/10.1056/NEJMra1606915

6. National Health Statistics and Medical Records Division (CU). Anuario Estadístico de Salud 2018. Havana: Ministry of Public Health (CU); 2019 [cited 2019 Jun 1]. 205 p. Available at: http://files.sld.cu/bvscuba/files/2019/04/Anuario -Electr\%C3\%B3nico-Espa\%C3\%B1ol-2018-ed -2019-compressed.pdf. Spanish.

7. Sanz GA. Estratificación del riesgo en los síndromes coronarios agudos: un problema no resuelto. Rev Esp de Cardiol [Internet]. 2007 [cited 2018 Mar 17];60 Suppl 3:23-30. Available at: https://www.revespcardiol.org/en-pdf-13113980. Spanish.

8. Buccheri S, Capranzano P, Condorelli A, Scalia M, Tamburino C, Capodanno D. Risk stratification after ST-segment elevation myocardial infarction. Expert Rev Cardiovasc Ther [Internet]. 2016 Dec [cited 2019 Oct 2];14(12):1349-60. Available at: http://dx.doi.org/10.1080/14779072 .2017.1256201

9. Song PS, Ryu DR, Kim MJ, Jeon KH, Choi RK, Park JS, et al. Risk scoring system to assess outcomes in patients treated with contemporary guideline-adherent optimal therapies after acute myocardial infarction. Korean Cir J [Internet]. 2018 Jun [cited 2019 Oct 2];48(6):492-504. Available at: https://e-kcj.org/DOlx.php?id=10.4070/ kcj.2017.0128

10. McNamara RL, Kennedy KF, Cohen DJ, Diercks $\mathrm{DB}$, Moscucci M, Ramee S, et al. Predicting inhospital mortality in patients with acute myocardial infarction. J Am Coll Cardiol [Internet]. 2016 Aug 9 [cited 2019 Oct 2];68(6):626-35. Available at: http://dx.doi.org/10.1016/j.jacc.2016.05.049

11. Morrow DA, Antman EM, Giugliano RP, Cairns R, Charlesworth A, Murphy SA, et al. A simple risk index for rapid initial triage of patients with STelevation myocardial infarction: an InTIME II substudy. Lancet [Internet]. 2001 Nov 1 [cited 2019 Oct 2];358(9293):1571-5. Available at: https:// doi.org/10.1016/S0140-6736(01)06649-1

12. Morrow DA, Antman EM, Charlesworth A, Cairns $R$, Murphy SA, de Lemos JA, et al. TIMI risk score for ST elevation myocardial infarction: a convenient, bedside, clinical score for risk assessment at presentation. An intravenous nPA for treatment of infarcting myocardium early II trial substudy. Circulation [Internet]. 2000 Oct 24 [cited 2019 Oct 2];102(17):2031-7. Available at: https://doi.org/10.1161/01.cir.102.17.2031

13. Shimony A, Grandi SM, Pilote L, Joseph L, O'Loughlin J, Paradis G, et al. Utilization of evidence-based therapy for acute coronary syndrome in high-income and low/middle-income countries. Am J Cardiol [Internet]. 2014 Mar 1 [cited 2019 Oct 2];113(5):793-7. Available at: https://dx.doi.org/10.1016/j.amjcard.2013.11.024

14. Rosselló X, Huo Y, Pocock S, Van de Werf F, Chin CT, Danchin N, et al. Global geographical variations in ST-segment elevation myocardial infarction management and post-discharge mortality. Int J Cardiol [Internet]. 2017 Oct 15 [cited 2019 Oct 2];245:27-34. Available at: https:// dx.doi.org/10.1016/j.ijcard.2017.07.039

15. Brogan RA, Malkin CJ, Batin PD, Simms AD, McLenachan JM, Gale CP. Risk stratification for ST segment elevation myocardial infarction in the era of primary percutaneous coronary intervention. World J Cardiol [Internet]. 2014 Aug 26 [cited 2019 Oct 2];6(8):865-73. Available at: https://dx.doi.org/10.4330/wjc.v6.i8.865

16. Granger CB, Goldberg RJ, Dabbous O, Pieper $\mathrm{KS}$, Eagle KA, Cannon CP, et al. Predictors of hospital mortality in the global registry of acute coronary events. Arch Intern Med [Internet]. 2003 Oct 27 [cited 2019 Oct 2];163(19):2345-53. Available at: http://doi.org/10.1001/archinte 163.19.2345

17. D'Ascenzo F, Biondi-Zoccai G, Moretti C, Bollati $\mathrm{M}$, Omedè $\mathrm{P}$, Sciuto $\mathrm{F}$, et al. TIMI, GRACE and alternative risk scores in Acute Coronary Syndromes: a meta-analysis of 40 derivation studies on 216,552 patients and of 42 validation studies on 31,625 patients. Contemp Clin Trials [Internet]. 2012 May [cited 2019 Oct 2];33(3):507-14. Available at: https://dx.doi.org/10.1016/j.cct.2012.01 .001

18. Ridker PM, Libby P, Buring JE. Risk Markers and the Primary Prevention of Cardiovascular Disease. In: Zipes DP, Libby P, Bonow RO, Mann DL, Tomaselli GF, editors. Braunwald's Heart disease. A textbook of cardiovascular medicine. 11th ed. Philadelphia: Elsevier; 2019. p.876-905.

19. Killip T 3rd, Kimball JT. Treatment of myocardial infarction in a coronary care unit: a two year experience with 250 patients. Am J Cardiol [Internet]. 1967 Oct [cited 2019 Oct 2];20(4):457-64. Available at: https://doi.org /10.1016/0002-9149(67)90023-9

20. Center for State Control of Medicines, Equipment and Medical Devices - CECMED (CU). Heberkinasa (Estreptoquinasa recombinante) Liofilizado para inyección (IV o IC). Titular del Registro Sanitario, Centro de Ingeniería Genética y Biotecnología (CIGB), Cuba. Número de Registro Sanitario: Heberkinasa® 1500000 UI: 1507. Fecha de Inscripción: Heberkinasa® 1500000 UI. 20 de marzo de 2000 [Internet]. Havana: Center for State Control of Medicines, Equipment and Medical Devices - CECMED (CU); 2000 Mar [cited 2019 Oct 2]. Available at: https://www.cec med.cu/registro/rcp/heberkinasar-1-500-000-ui -estreptoquinasa-recombinante. Spanish.

21. Bayés de Luna A. Bases de la electrocardiografía. De las variantes de la normalidad a los patrones diagnósticos (III): Isquemia, lesión y necrosis. Vol 3. Barcelona: Prous Science; 2007.129 p. Spanish.

22. Thygesen K, Alpert JS, Jaffe AS, Chaitman BR, Bax JJ, Morrow DA, et al. Fourth universal definition of myocardial infarction (2018). J Am Coll Cardiol [Internet]. 2018 Oct 30 [cited 2019 Oct 2];72(18):2231-64. Available at: https://doi .org/10.1016/j.jacc.2018.08.1038

23. Mitchell C, Rahko PS, Blauwet LA, Canaday B, Finstuen JA, Foster MC, et al. Guidelines for Performing a Comprehensive Transthoracic Echocardiographic Examination in Adults: Recommendations from the American Society of Echocardiography. J Am Soc Echocardiogr [Internet]. 2019 Jan [cited 2019 Oct 2];32(1):1-64. Available at: http://dx.doi.org/10.1016/j.echo .2018.06.004

24. Teruel JLG, Catalán SB. Valoración de afección renal, disfunción renal aguda e hiperpotasemia por fármacos usados en cardiología y nefrotoxicidad por contrastes. Rev Esp Cardiol [Internet] 2011 Dec 1 [cited 2019 Oct 2];64(12):1182-92. 
Available at: https://doi.org/10.1016/j.recesp 2011.08.012. Spanish

25. Center for State Control of Medicines, Equipment and Medical Devices - CECMED (CU). Registro de electrocardiógrafo digital de tres canales. Titular del Registro Sanitario, Instituto Central de Investigación Digital ICID. Fecha de Inscripción: 2008 febrero 28 [Internet]. Havana: Center for State Control of Medicines, Equipment and Medical Devices - CECMED (CU); 2008 Feb 28 [cited 2018 Sep 2]. 55 p. Available at: http://www.cecmed.cu/ sites/default/files/adjuntos/registro_equipos_m/ registro_em_2004_2007.pdf. Spanish.

26. Postema PG, Wilde AAM. The measurement of the QT interval. Curr Cardiol Rev [Internet]. 2014 Aug [cited 2019 Oct 2];10(3):287-94. Available at: https://doi.org/10.2174/157340 3X10666140514103612

27. Smulyan H. QT interval: Bazett's Correction corrected. J Electrocardiol [Internet]. 2018 Nov-Dec [cited 2019 Oct 2];51(6):1009-10. Available at: http://dx.doi.org/10.1016/j.jelectro card.2018.08.013

28. Stankovic I, Putnikovic B, Janicijevic A, Jankovic M, Cvjetan R, Pavlovic S, et al. Myocardial mechanical and QTc dispersion for the detection of significant coronary artery disease. Eur Heart $\mathrm{J}$ Cardiovasc Imaging [Internet]. 2015 Sep [cited 2019 Oct 2];16(9):1015-22. Available at: http:// dx.doi.org/10.1093/ehjci/jev029

29. Acosta Martínez J, Berruezo A. Abordajes alternativos a la fracción de eyección en la estratificación de riesgo de arritmias ventriculares. Cardiocore [Internet]. 2017 Jan-Mar [cited 2019 Oct 2];52(1):7-10. Available at: http://dx.doi .org/10.1016/j.carcor.2016.12.002. Spanish.

30. World Medical Association. Declaration of Helsinki: ethical principles for medical research involving human subjects. JAMA [Internet]. $2013 \mathrm{Nov}$ 27 [cited 2018 Jun 13];310(20):2191-4. Available at: https://jamanetwork.com/journals/jama/full article/10.1001/jama.2013.281053

31. Van Delden JJM, Van der Graaf R. Revised CIOMS International Ethical Guidelines for Health-Related Research Involving Humans. JAMA [Internet]. 2017 Jan 10 [cited 2019 Sep 11];317(2):135-6. Available at: https://jamanet work.com/journals/jama/article-abstract/2592245

32. Helmy H, Abdel-Galeel A, Taha Kishk Y, Mohammed Sleem K. Correlation of corrected QT dispersion with the severity of coronary artery disease detected by SYNTAX score in non-diabetic patients with STEMI. Egypt Heart J [Internet]. 2017 Jun [cited 2019 Oct 2];69(2):111-7. Available at: http://dx.doi.org/10.1016/j.ehj.2016.12.001

33. Huang J, Peng X, Fang Z, Hu X, Zhou S. Risk assessment model for predicting ventricular tachycardia or ventricular fibrillation in ST-segment elevation myocardial infarction patients who received primary percutaneous coronary intervention. Medicine [Internet]. 2019 Jan [cited 2019 Oct 2];98(4):e14174. Available at: https://dx.doi .org/10.1097/MD.0000000000014174

34. Yu Z, Chen Z, Wu Y, Chen R, Li M, Chen X, et al. Electrocardiographic parameters effectively predict ventricular tachycardia/fibrillation in acute phase and abnormal cardiac function in chronic phase of ST-segment elevation myocardial infarction. J Cardiovasc Electrophysiol [Internet]. 2018 May [cited 2019 Oct 2];29(5):756-66. Available at: http://dx.doi.org/10.1111/jce.13453

35. Rodríguez-Jiménez AE, Cruz-Inerarity $\mathrm{H}, \mathrm{Ne}-$ grin-Valdés T, Fardales-Rodríguez R, ChávezGonzález E. Corrected QT-interval dispersion: an electrocardiographic tool to predict recurrence of myocardial infarction. MEDICC Rev [Internet]. 2019 Apr-Jul [cited 2019 Oct 2];21(2-3):22-8 Available at: http://mediccreview.org/wp-content/ uploads/2019/07/MR-AprilJuly2019-OR-rodri guez-corrected-qt.pdf

36. Rivera-Fernández R, Arias-Verdú MD, GarcíaParedes T, Delgado-Rodríguez M, ArboledaSánchez JA, Aguilar-Alonso E, et al. Prolonged QT interval in ST-elevation myocardial infarction and mortality: new prognostic scale with QT, Killip and age. J Cardiovasc Med [Internet]. 2016 Jan [cited 2019 Oct 2];17(1):11-9. Available at: https://doi.org/10.2459/JCM.0000000000000015

37. Bordejevic DA, Caruntu F, Mornos C, Olariu I, Petrescu L, Tomescu MC, et al. Prognostic impact of blood pressure and heart rate at admission on in-hospital mortality after primary percutaneous intervention for acute myocardial infarction with ST-segment elevation in western Romania. Ther Clin Risk Manag [Internet]. 2017 Aug 23 [cited 2019 Oct 2];13:1061-8. Available at: http://dx.doi.org/10.2147/TCRM.S141312

38. Vavalle JP, van Diepen S, Clare RM, Hochman JS, Weaver WD, Mehta RH, et al. Renal failure in patients with ST-segment elevation acute myocardial infarction treated with primary percutaneous coronary intervention: predictors, clinical and angiographic features, and outcomes. Am Heart J [Internet]. 2016 Mar 1[cited 2019 Oct 2];173:57-66. Available at: http://dx.doi .org/10.1016/j.ahj.2015.12.001

39. Gutiérrez HB, Martos Benítez FD. Valor pronóstico de la función renal a corto plazo en pacientes con infarto agudo de miocardio. Rev Colombiana Cardiol [Internet]. 2018 Jan 1 [cited 2019 Oct 2];25(1):26-32. Available at: https://doi. org/10.1016/j.rccar.2017.08.013. Spanish.

40. Pocock S, Bueno H, Licour M, Medina J, Zhang $\mathrm{L}$, Annemans L, et al. Predictors of one-year mortality at hospital discharge after acute coronary syndromes: a new risk score from the EPICOR (long-tErm follow uP of antithrombotic management patterns in acute coronary syndrome patients) study. Eur Heart J Acute Cardiovasc Care [Internet]. 2015 Dec [cited 2019 Oct 2];4(6):509-17. Available at: http://dx.doi.org /10.1177/2048872614554198

41. Ding XS, Wu SS, Chen H, Zhao XQ, Li HW. High admission glucose levels predict worse shortterm clinical outcome in non-diabetic patients with acute myocardial infraction: a retrospective observational study. BMC Cardiovasc Disord [Internet]. 2019 Jul 4 [cited 2019 Oct 2];19(1):163. Available at: https://doi.org/10.1186/s12872-019 $-1140-1$

42. Kojima T, Hikoso S, Nakatani D, Suna S, Dohi T, Mizuno $\mathrm{H}$, et al. Impact of hyperglycemia on longterm outcome in patients with ST-segment elevation myocardial infarction. Am J Cardiol [Internet]. 2020 Mar 15 [cited 2020 Mar 20]. Available at: https://doi.org/10.1016/j.amjcard.2019.12.034

43. Kosiborod M. Hyperglycemia in acute coronary syndromes: from mechanisms to prognostic implications. Endocrinol Metab Clin North Am [Internet] 2018 Mar [cited 2019 Oct 2];47(1):185-202. Available at: https://doi.org/10.1016/..ecl.2017.11.002

44. Bhar-Amato J, Davies W, Agarwal S. Ventricular Arrhythmia after Acute Myocardial Infarction: 'The Perfect Storm'. Arrhythm Electrophysiol Rev [Internet]. 2017 Aug [cited 2019 Oct 2];6(3):134-9. Available at: http://dx.doi.org/10.15420/aer.2017.24.1

45. Farré N, Fort A, Tizón-Marcos H, Recasens L, Vaquerizo B, Serrat R, et al. Epidemiology of heart failure in myocardial infarction treated with primary angioplasty: Analysis of the Codi IAM registry. REC: CardioClinics [Internet]. 2019 JanMar [cited 2019 Oct 2];54(1):41-9. Available at: https://doi.org/10.1016/j.rccl.2019.01.014

46. Shah M, Patil S, Patel B, Agarwal M, Davila $\mathrm{CD}$, Garg $\mathrm{L}$, et al. Causes and predictors of 30-day readmission in patients with acute myocardial infarction and cardiogenic shock. Circ Heart Fail [Internet]. 2018 Apr [cited 2019 Oct 2];11(4):e004310. Available at: http://dx.doi .org/10.1161/CIRCHEARTFAILURE.117.004310

47. Shah RU, de Lemos JA, Wang TY, Chen AY, Thomas L, Sutton NR, et al. Post-hospital outcomes of patients with acute myocardial infarction with cardiogenic shock: findings from the NCDR. J Am Coll Cardiol [Internet]. 2016 Feb 23 [cited 2019 Oct 2];67(7):739-47. Available at: http://dx.doi.org/10.1016/j.jacc.2015.11.048

48. Bedetti G, Gargani L, Sicari R, Gianfaldoni ML, Molinaro S, Picano E. Comparison of prognostic value of echocardiographic risk score with the Thrombolysis in Myocardial Infarction (TIMI) and Global Registry in Acute Coronary Events (GRACE) risk scores in acute coronary syndrome. Am J Cardiol [Internet]. 2010 Dec 15 [cited 2019 Oct 2];106(12):1709-16. Available at: https://doi.org/10.1016/j.amjcard.2010.08.024

49. Schwaiger JP, Reinstadler SJ, Tiller C, Holzknecht M, Reindl M, Mayr A, et al. Baseline LV ejection fraction by cardiac magnetic resonance and $2 \mathrm{D}$ echocardiography after ST-elevation myocardial infarction - influence of infarct location and prognostic impact. Eur Radiol [Internet]. 2020 [cited 2020 Feb 21];30(1):663-71. Available at: https://link.springer.com/content/pdf/10. 1007\%2Fs00330-019-06316-3.pdf

50. Argimon-Pallas JM, Jiménez-Villa J. Métodos de investigación clínica y epidemiológica. 5th ed. Barcelona: Elsevier; 2019. 496 p. Spanish.

\section{THE AUTHORS}

Ailed Elena Rodríguez-Jiménez (Corresponding author: ailedrj@infomed.sld.cu), physician with dual specialties in family medicine and cardiology, and a master's degree in satisfactory longevity. Associate professor, Camilo Cienfuegos Provincial Hospital (HPCC), Sancti Spíritus, Cuba. https://orcid.org/0000-0001-8559-6867

Tessa Negrín-Valdés, physician with dual specialties in internal medicine and cardiology. Associate professor, HPCC, Sancti Spíritus, Cuba. https://orcid.org/0000-0001-5486-1373

Hugo Cruz-Inerarity, cardiologist. Teaching professor, HPCC, Sancti Spíritus, Cuba. https:// orcid.org/0000-0001-8787-6520

Luis Alberto Castellano-Gallo, cardiologist. HPCC, Sancti Spíritus, Cuba. https://orcid .org/0000-0003-1959-0656

Elibet Chávez-González, cardiologist with a doctorate in medical sciences. Associate professor. HPCC, Sancti Spíritus, Cuba. https://orcid. org/0000-0003-2246-2137

Submitted: November 8, 2019

Approved for publication: July 2, 2020

Disclosures: None 